\title{
CHARACTERIZATION OF PHANEROGAM COMMUNITIES \\ (Posidonia oceanica and Cymodocea nodosa) \\ USING SIDE-SCAN-SONAR IMAGES
}

Siljeström, Patricia A.(1); Rey, Jorge (2) and Moreno, Adela (1)

(1) Instituto de Recursos Naturales y Agrobiología (CSIC). Apartado 1052, 41080 Sevilla.

(2) ESGEMAR, S.A., Espacio 4, 29006 Málaga.

Corresponding author: Patricia A. Siljeström, IRNAS-CSIC, Apartado 1052, 41080 Sevilla (Spain). Phone \# + 34 (9) 54624711 ; Fax \# + 34 (9) 54624002 ;

e-mail: PATRICIA@IRNASE.CSIC.ES

\begin{abstract}
This paper presents the most appropriate image-processing techniques available at the present time to differentiate two different seameadow communities, Posidonia oceanica and Cymodocea nodosa. The pre-processing program is an integral part of the sonar system and, therefore is not discussed in this paper. We propose a methodology based on unsupervised classification to chart and monitor these meadows, so fundamentally important to the mediterranean ecosystem. The images used for discussion were of seabottoms in the Cabrera Archipielago in the Mediterranean Sea.
\end{abstract}

Keywords: Image processing, side-scan-sonar, seagrass meadows, Cabrera Archipelago, Mediterranean sea. 


\section{INTRODUCTION}

The last two decades have seen rapid developments in the use of digital data collected by remote sensing instruments. Side-scan-sonar is an active remote sensing instrument that emits a beam of acoustical waves and differentially analyses the returning waves reflected by underwater structures to produce two-dimensional images, called sonographs (Abarzuza, 1991; Sutton, 1979; Chavez, 1986).Currently, several different types of side-scan-sonar are used in a large number of underwater studies (Rey and Díaz del Río, 1989; De Andrés et al., 1991; Newton and Stefanon, 1975; Gloux, 1984; Duck and McManus, 1990). Because sidescan-sonar can produce visual images of the seabottom it has now become a most important and powerful tool for submarine research (Sanz and Rey, 1983; Duck et al., 1993).

Sonographs, in effect, measure and differentiate the acoustic reflectance properties of geomorphic features of the sea floor and of any artifacts that may lie on the seafloor surface or float in the water column. Consequently, in a number of ways, imaging-sonar is analogous to side-looking radar (Chavez, 1986).

This paper describes the application of computer processing techniques to enhance digital images produced by side-scan-sonar to attenuate the signal noise that greatly reduces the information content of sonar-images. Our aim was to discover, under difficult working conditions, the optimum information-extraction technique or image enhancement methodology that would help us to carry out future submarine studies in the same area more effectively, more quickly and more easily.

\section{PHANEROGAM SEAMEADOWS}

\subsection{Posidonia oceanica}


Posidonia seameadows are extensive communities of the marine phanerogam Posidonia oceanica (L.) Delile, an endemic species in the Mediterranean Sea. The complex vegetable structure of these meadows contains a large number of sensitive biological systems that are of fundamental importance to the Mediterranean marine ecosystem. Firstly, the massive enclosed volume of still water between the countless long leaves of the meadow plants help floating particulate organic matter to sediment to the bottom and accumulate between the dense matrix of Posidonia plant rhizomes on the seabed (Augier, 1986; Ben Mustapha \& Hattour, 1987). They also produce high levels of oxygen per $\mathrm{m}^{2}$ and organic detritus when they die (Boudouresque and Meinesz, 1982; Anonyme, 1991). They are the principal contributor to the great biological diversity of the marine ecosystem, because a remarkably high number of species colonise these meadows (Anonymous, 1991). Moreover more than $30 \%$ of the seagrass biomass production is exported to the deeper waters of the Mediterranean basin (Augier, 1986) and become adult fish to sustain the fish stocks of the commercial fisheries. Consequently, damage to the meadows effectively reduces many stocks of commercial fish species.

\subsection{Cymodocea nodosa}

Cymodocea nodosa (Ucria) Ascherson, is a phanerogam, very similar to Posidonia, but with an adventurous pioneer character and therefore is often the vanguard for the subsequent settlement by Posidonia .

Posidonia meadows are in an alarming state of regression, due to the deterioration of environmental conditions in the Mediterranean Sea. Until the present moment, the cartography and monitoring of these sea meadows was done by semidetailed aerial photography (Lefevre et al., 1984), which gives very good results in clear waters up to $10 \mathrm{~m}$ depth and using punctual diving. In other cases, where aerial photography was not practical, 
surveys and sampling was carried out by divers at predetermined points (Ramos-Esplá, 1984). Therefore, any way that permits this species to be monitored must be exploited, and particularly those new methodologies that permit extensive surveys without disturbing the delicate ecosystem of the meadows.

The phanerogam meadows studied in this work are located in the Cabrera Archipielago, that was declared Natural Terrestial and Marine National Park in 1993 (Fig. 1). All the vegetable communities mentioned in this work were very precisely located and mapped by differential Global-Positioning-Satellite navigation (GPS). They were also visually inspected and sampled by divers, and the samples were analysed.

Fig. 1 goes approximately here

\section{DATA ACQUISITION AND PROCESSING SYSTEMS}

\subsection{Sonograph recording}

The sidescan system used in this study is a Klein Hydroscan model 595, which emits simultaneously two beams, each with a different-frequency (100 and $500 \mathrm{kHz})$. For this 
present work we used a maximum slant range of $100 \mathrm{~m}$ per channel on each side of the towfish transducer. The pixel resolution was $1 \mathrm{~m}$.

The instrument itself applies the anamorphic and slant-range corrections to the raw data, using navigation and depth data supplied from the ship computer log system. This quantitative geometric processing eliminates the lateral and longitudinal distortions caused by the slant of the beam and and fluctuations in the speed of the vessel and its sensor over the seabed. In this way the system generates accurate analog isometric images (thermal paper) and, simultaneously stores the digital data on tape. The pre-processing algorithms are specifically written to conform to the unique data-acquisition characteristics of the Klein system (with specific geometric and radiometric distortions) and so we do not discuss them here.

\subsection{Image processing}

The image enhancement processes, carried out onshore, aim to improve the recognition of objects or patterns in a digital image to permit their more effective visual interpretation or digital classification (Chavez, 1986; Jan and Minot, 1989; Cervenka and de Moustier, 1993).

The original sonographs were scanned at a 250 dpi resolution and were processed by the ISI2 software that runs on an Intergraph platform.

Firstly, image frames produced by the two different frequencies (presented in separate bands) that show the same site were registered with an interactive image-to-image process that selects common reference points in both images. Afterwards, a first order mapping model that integrated one scene with the other was constructed. The resampling was based upon nearest-neighbour interpolation. The mean standard errors for the predictions of control 
points in the master image from those in the slaves were less than $1 / 4$ pixel in both row and column.

Later, the contrast of each subscene was enhanced independently, to improve visual interpretation. Image processing must take into account that these images are partially obscured by an overlay of continuous interference (noise) pattern produced by the unwanted reception of other waves, either acoustic, electric or electromagnetic, extraneous to those used by the sonar system (Miller et al., 1991). Thus, several image enhancement processes must be applied directed towards spatial enhancement and textural analysis, fundamentally, to facilitate the visual interpretation and information extraction (Fox et al ., 1990; Siljeström et al., 1995).

\section{RESULTS AND DISCUSSION}

The following four images were selected to illustrate special features:

\subsection{Posidonia. ext}

This first image is of a Posidonia oceanica bed on a flat sandy bottom; its huge size (2336 x 4228 pixels) imposes a limit on the transformations that can be applied.

The best results were given when we applied a non-supervised classification based on the isodata algorithm and minimum-distance classifier. The image (Fig. 3, A ) differentiates well the specific growing-structure of Posidonia vegetation (density, cover) with tones of red that contrast with the blue tones of the seabottom. Note that the $100 \mathrm{kHz}$ band image is in the upper part, while the $500 \mathrm{kHz}$ image is below.

The edges of both channels (100 and $500 \mathrm{kHz}$ ) are rather blurred and confused and the plants directly under the ship show a strong reflection due to the characteristic morphological structure of the Posidonia beds. The plants have long, very reflective laminar leaves and are about $1 \mathrm{~m}$ high, but, most importantly, they have a very complex and strong rhizome structure 
(10 to $15 \mathrm{~cm}$ high) that appears in the images as a well defined topographic feature. This spatial distribution pattern is defined as an erratic sub-parallel filiform structure (Siljeström et al., 1994). This erratic structure has the great advantage for this type of analysis that it is large enough to be identified with sufficient detail at the range scale used.

\subsection{Possi.ext}

The second image (Possi.ext) is of two superimposed subscenes of the previous one taken with $100 \mathrm{kHz}$, and with $500 \mathrm{kHz}$ (Possil and 5.ext, respectively). Figs. $2 \mathrm{~A}$ and 2B show the raw images for comparison with the processed ones. These smaller subscenes $(594 \mathrm{x}$ 571 pix.) permit a great number of transformations to be applied.

Note here that at a higher frequency, the spatial resolution has increased, but the beam reach decreases (Abarzuza, 1991, Siljeström et al., 1995). As mentioned above, the Posidonia oceanica plant communities are sufficiently large and extensive to be detected with the 100 $\mathrm{kHz}$ band that, in addition, has a longer beam reach that gives more information at the edges of the image. This $100 \mathrm{kHz}$ band is usually noisier than the $500 \mathrm{kHz}$ one. However, in spite of this, it gives a much better overall view of the Posidonia beds.

In these detailed raw images, the noise in the $100 \mathrm{kHz}$ band (Possi 1.ext, Fig. 2, A) is more obvious, but the definition of the meadow structure is better than that of the $500 \mathrm{kHz}$ image (Possi 5.ext, Fig. 2, B). Fig. 4, B shows the image obtained after applying a nonsupervised classification with isodata and a post-classification, 3 x 3 mode filter. The Posidonia vegetation becomes black and changes to grey and yellow near the image edges. The varying colors of the different grades of Posidonia classes are related to their foliage density and to their distance from the acoustic source. 
Here goes the Figure 2 (Example of raw images in two frequencies)

Even though the $500 \mathrm{kHz}$ image, (Possi 5.ext) is cleaner and has a better pixel resolution, it gives less structural information. Fig. 4, C, shows the result of applying an unsupervised classification based on k-means algorithm. This has enhanced only the dense areas of Posidonia, while the other areas with sparse vegetation are blurred.

Finally, a non supervised classification with k-means was applied to both extracts. The resulting thematic map (Fig. 4, D) clearly differentiates the dense Posidonia vegetation (dark-green) and the sparse vegetation (light-green) from the bottom (light-blue to white).

These images have a clear interpretation due to the strong structure of the vegetation (already mentioned) and to the detailed scale. In general, classifications offer very good results in enhancing aspects as different leave densities on the same rhizome.

\subsection{Bomb.ext}

The third image studied (bomb.ext), is also of a flat, sandy bottom covered by a Posidonia oceanica community with circular clearings denuded of vegetation. These round 
denuded areas were caused by the explosions of practice shells from warships firing at one of the islands of the archipielago.

Because of the enormous size of the seabottom impact-site to be studied ( more than $30 \mathrm{~m}$ diameter), we selected and cut two sub-scenes of $1171 \times 1102$ pixels from an original image frame of the same scene in each band. Later, we superimposed one coincident subimage on the other. The $100 \mathrm{kHz}$ band, as in the previous case, has more noise but, on the other hand, it has much better contrast, a longer beam reach and a more adequate spatial resolution for a monitoring study of this type. One of the echo sensors had a calibration error so both sub-scene images contain dark tones in their lower parts. The best results were obtained when we applied a false color coding: red was assigned to the $100 \mathrm{kHz}$ extract, green to the $500 \mathrm{kHz}$ one and red to the resulting image of the $100 \mathrm{kHz}$ subscene modified by a Sobel edge-detector filter. The resultant image (Fig. 3, E) differentiates well the deteriorated state of the Posidonia communities and shows clearly the enormous devastation caused by the shells.

Unsupervised classifications gave unsatisfactory images and so they are not discussed in the paper.

The processing of the images at this third site was particularly effective, because it allowed us to monitor the progressive recovery of areas of a Posidonia meadow. To be able to obtain in the future visual information about the recovery process of submarine Posidonia and other seagrass meadows will be an enormous help to investigators who have to evaluate other damaged meadows in the Mediterranean Sea.

\subsection{Cymodocea.ext}

The fourth image is of a Cymodocea nodosa (Ucria) Ascherson meadow. Two subscenes ( $927 \times 739$ pixels) of the same visual field in both the 100 and the $500 \mathrm{kHz}$ band were 
selected, extracted and accurately superimposed. The extracted sub-scenes correspond just to half of the seabed swept by the sonar beam; the lower edge of the image is directly under the ship and the upper edge corresponds to the furthest reach of the top of the sloping beam. This geometric relationship has great practical significance; it means that the $500 \mathrm{kHz}$ band that gives more spatial resolution, but has a shorter beam reach, will give very little information about structures at the outside edge of the ribbon of seabed surveyed by the sonar beam.

Firstly, we applied an unsupervised classification to the $100 \mathrm{kHz}$ extracted sub-image with an isodata algorithm. The resultant thematic map (Fig. 3, F) depicts three classes (two for the water and one for the plants). The area of seabed covered by a Cymodocea sp. community, is yellow. Note the high-reflectance characteristic of this seagrass species, in spite of its small dimensions. Its leaves are very narrow (0.3 cm approx.) and quite short (about 20 to $25 \mathrm{~cm}$ ). In these images, this species of meadow displays no characteristic structural pattern, but when we inspected more recent images, we discerned a faint dendritic pattern that might possibly serve in the future as a diagnostic feature when seen in processed images of good quality.

Unsupervised classification was later applied to both bands, and gave a much better result. The longer beam reach of the $100 \mathrm{kHz}$ sub-scene extract, when superimposed on the $500 \mathrm{kHz}$ subscene, gave improved spatial resolution that also depicted vegetation density. The resulting thematic map (Fig. $3 \mathrm{G}$ ) shows dense Cymodocea vegetation in red which becomes orange and then yellow as the meadow becomes less dense and then sparse. The seabottom appears in tones of blue. 
Figure 3 : processed images. All of them go in one page.

\section{CONCLUSIONS}

This present work demonstrated that side scan sonar was a most effective instrument for studying, rapidly mapping and determining the degree of deterioration or recuperation of phanerogam meadows of Posidonia sp. or Cymodocea sp. The experience suggests that it will become a powerful tool for future cartographic studies of coastal vegetation of this type. 
The several image enhancement processes greatly increased the extraction of meaningful information from the different types of sonographs. The different noise-reducing filters and the unsupervised classifications made visual interpretation by human observers easier and more precise.

The unsupervised data classifications with their isodata algorithm and maximum likelihood classifier gave really outstanding results; they improved texture and pattern recognition better than any of the other methods applied. The class separations effectively differentiated the different phanerogam communities and was able to determine particularly well the degrees of deterioration or recovery from damage of Posidonia meadows: principally because of their characteristic structural pattern.

Although the $100 \mathrm{kHz}$ images usually contained more noise, they gave more information than those given by the $500 \mathrm{kHz}$ channel, because they have a longer acoustic beam that gives adequate spatial resolution for the type of future studies that we propose in this paper.

Additional frequency bands at $50 \mathrm{kHz}$ and $200 \mathrm{kHz}$, or even others, would allow us to carry out a multifrequency study.

The excellent results of this application of image-processing to side-scan sonographs suggest that the combined method will soon become an extremely valuable tool for surveying quickly and easily, and mapping in detail, underwater seagrass meadows. Underwater surveys that use image-enhanced side-scan-sonar sononographs could be a cost-effective solution to the problem of monitoring these submarine problem areas.

\section{ACKNOWLEDGEMENTS}

The facilities received by the Hydrographic Institute (Army) in Cadiz for scanning the images are gratefully acknowledged. We also thank the Spanish Oceanographic Institute 
(IEO) for the images used in this paper that correspond to the PASCA 1411 project. The authors also wish to thank Mr. D. W. Schofield for his critical review of the English version.

\section{REFERENCES}

Abarzuza, J. (1991), Sonar de barrido lateral y penetradores de sedimentos. Instituto Hidrográfico de la Marina, Cadiz: 207 pp.

Anonyme, (1991), Posidonia oceanica meadows in the Mediterranean Sea: Status and Distribution. Mediterranean Sea Project, Greenpeace International: 25 pp.

Augier, H. (1986), Le herbier a Posidonia oceanica, son importance pour le littoral mediterraneen, sa valeur comme indicateur biologique de líetat de santéde la mer, son utilisation dans la surveillance du millieu, les bilans ecologiques et les etudes díimpact. Vie marien, Fr, 7: 85-113.

Ben Mustapha, A., and Hattour, A , (1987), Posidonia meadows in the Coast of Tunisia: Gulf of Hammamet. Greenpeace Mediterranean Project Report: 19 pp.

Boudouresque, C.F. and Meinesz, A. (1982), Decouverte de líherbier de posidonie. Parc. National Port-Cross, Report, 4: 80 pp.

Cervenka, P. and de Moustier, C. (1993), Side Scan Sonar Image Processing Techniques, IEEE Journal of Oceanic Engineering, vol 18, 2 : 108-122.

Chavez, P.S.-(1986), Processing techniques for digital sonar images from GLORIA. Photogrammetric Engineering and Remote Sensing, vol 52, 8: 1133-1145.

De Andrés, J.R.; Rey, J. and Salinas, J.M. (1991), Detección de arribazones submarinos de algas por métodos indirectos: un nuevo procedimiento. Technical Report of the Instituto Español de Oceanografía, 93: 38 pp. 
Duck, R.W. and McManus, J. (1990), Uses of sidescan sonar in lakes and reservoires. In: 6thInternational IAEG Congress, (D.G. Price Ed.), Delf Univ. of Technology: 10811085.

Duck, R.W.; McManus, J. and Lord, J. (1993), Seismicity and Bed Sediment Morphology in a Perthshire Reservoir, UK., Geomorphology and Sedimentology of Lakes and Reservoirs: 225-239.

Fox, C.G.; Jones, F.J. and Lau, T.K. (1990), Constrained Iterative deconvolution Applied to Sea MARC I Sidescan Sonar Imagery. IEEE Journal of Oceanic Engineering, vol 15, n1: 24-31.

Gloux, B. (1984), Méthodes acoustiques et informatiques appliquèes la cartographie rapide et detaillèe des herbiers. In: International Workshop on Posidonia oceanica Beds (C.F.Boudouresque, A. Jeudy de Grissac and J. Olivier, Ed.), GIS Posidonie publ., 1: 45-48, Fr.

Jan, D. and Minot, J. (1989), Les traitements díimage en sonar lateral. Le Onde Electrique, vol $\quad 69,3: 13-19$.

Lefevre, J-R.; Valerio, C. and Meinesz, A. (1984), Optimisation de la téchnique de la photographie aerienne pour la cartographie des herbiers des Posidonies. In: International Workshop on Posidonia oceanica Beds, (C.F. Boudouresque, A. Jeudy de Grissac and J. Olivier, Ed.), GIS Posidonie Publ., Fr. 1: 49-55 .

Miller, R.L.; Swan, F.S. and Cheng, C.F. (1991), Digital Preprocessing Techniques for GLORIA II Sonar Images. Geo-Marine Letters, 11: 23-31.

Newton, R.S. and Stefanon, A. (1975), Application of side scan sonar in marine biology, Marine Biology, 31: 287-291.

Ramos-Esplá, A.A. (1984), Cartografía de la pradera superficial de Posidonia oceanica en la bahía de Alicante (SE España). In: International Workshop on Posidonia oceanica 
Beds (C.F. Boudouresque, A. Jeudy de Grissac and J. Olivier, Ed.), GIS Posidonie publ., Fr., 1: 57-61.

Rey, J. and Díaz del Río, V. (1989), Cartografía de los fondos marinos en la Bahía de Palma

(Baleares, España) : distribución de las praderas vegetales y sedimentos superficiales.

In: International Workshop on Posidonia oceanica Beds, (C.F. Boudouresque, A.; Meinesz, E. Fresi and V. Gravez ,Ed.): 2: 29-41., GIS Posidonie Publ., Fr.

Siljeström, P.; Moreno, A. and Rey, J. (1994), Caracterización de comunidades de Posidonia oceanica a través del tratamiento digital de sonografìas. Proceedings VIII Symposium Ibérico de Bentos Marino: 107-107.

Siljeström, P.; Moreno, A. and Rey, J. (1995), Seafloor characterization through side scan sonar image processing. International Journal of Remote Sensing, vol 16, 4: 625-632.

Sanz, J.L. and Rey, J. (1983), Estudio de campos de algas con sonar de barrido lateral. Bulletin of the Instituto Español de Oceanografía, vol 1, 1: 115-118.

Sutton, J.L. (1979), Underwater acoustic imaging. Proceedings of IEEE, April 1979, vol 67, 4: $554-566$.

\section{CAPTIONS TO FIGURES}

Fig. 1: Geographical location of the studied area.

Fig. 2 : Example of raw images
A) Corresponds to Possi 1.ext, taken with $100 \mathrm{kHz}$.
B) Same location, Possi 5.ext, corresponds to $500 \mathrm{kHz}$ 
Fig. 3 : Color processed images:

A ) Unsupervised classification applied to an image corresponding to a Posidonia oceanica meadow, taken in both frequencies, 100 and $500 \mathrm{kHz}$.

B) Unsupervised classification applied to Possi 1.ext.

C) Unsupervised classification applied to Possi 5.ext

D) Unsupervised classification applied to both extracts, Possi 1.ext and Possi 5.ext.

E) False color composition Bomb.rgb

F) Unsupervised classification applied to Cymodocea 1.ext

G) Unsupervised classification applied to both extracts, Cymodocea 1.ext and Cymodocea 5.ext. 